\title{
THE POLOVTSIAN STONE WOMAN FROM THE OUTSKIRTS OF THE DENISOVO-NIKOLAEVKA FARMSTEAD
}

\author{
Aleksey Yu. Danilchenko \\ Objects of Cultural Heritage - Project CJSC, Rostov-on-Don, Russian Federation
}

\begin{abstract}
This research is devoted to the publication and analysis of the Polovtsian stone sculpture discovered in the summer of 2018 in the North-Eastern Azov region, on the outskirts of the farmstead Denisovo-Nikolaevka, Kuibyshev district of the Rostov region. The undamaged condition of the found specimen allows to determine its type, to draw analogies with similar findings based on early published materials, as well as collections of local museums. Analyzing archaeological discovery, we can conclude that a male Polovtsian stone statue was discovered. As for the dating of the stone, with a high degree of caution it can be attributed to a group of later Polovtsian statues of the late $12^{\text {th }}$ - early $13^{\text {th }}$ centuries. Such findings are very rare and can give us new knowledge about the level of development of culture, fine arts and religious beliefs of the Polovtsians.

Key words: Polovtsian stone woman, stone statues of the South Russian and Volga steppes, stone sculpture, statue, historical source, type, typology.

Citation. Danilchenko A.Yu., 2018. The Polovtsian Stone Woman from the Outskirts of the Denisovo-Nikolaevka Farmstead. The Lower Volga Archaeological Bulletin, vol. 17, no. 2, pp. 128-134. (in Russian). DOI: https://doi. org/10.15688/nav.jvolsu.2018.2.10
\end{abstract}

УДК $902.01+902.21$

Дата поступления статьи: 10.09.2018

ББК Т4 63.4(2) Дата принятия статьи: 23.10.2018

\section{ПОЛОВЕЦКАЯ КАМЕННАЯ БАБА С ОКРАИНЫ ХУТ. ДЕНИСОВО-НИКОЛАЕВКА}

\author{
Алексей Юрьевич Данильченко \\ ЗАО «Объекты культурного наследия - проект», г. Ростов-на-Дону, Российская Федерация
}

\begin{abstract}
Аннотация. Данная работа посвящена публикации и анализу половецкой каменной скульптуры, обнаруженной летом 2018 г. в северо-восточном Приазовье, на окраине хут. Денисово-Николаевка Куйбышевского района Ростовской области. Сохранность найденного экземпляра позволяет определить его тип, провести аналогии с подобными находками, опираясь на раннее опубликованные материалы, а также коллекции местных музеев. Анализируя археологическую находку, можно сделать вывод, что автором была обнаружена половецкая мужская каменная статуя. Говоря о датировке каменного идола, его можно отнести к группе более поздних половецких изваяний конца XII - начала XIII века. Подобные находки являются большой редкостью и способны дать нам новые знания об уровне развития культуры, изобразительного искусства, религиозных представлениях половцев.

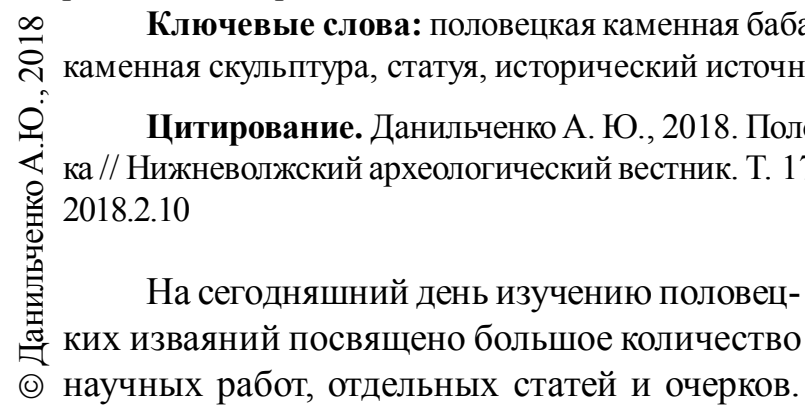

Активная работа в этом направлении ведется с конца XIX в., а именно: сбор информации о найденных каменных изваяниях, их учет,
\end{abstract}


классификация и систематизация полученных знаний. Так, тенденции более тщательного подхода в изучении проблематики были отображены в трудах А.И. Пискарева. Позже попытки дать классификацию каменных баб были предприняты А.С. Уваровым. Н.И. Веселовский привел подробную историографию вопроса о каменных половецких статуях в своем труде от конца XVIII в. до 1915 года [Веселовский, 1915].

Наряду с изучением каменных идолов европейских степей учеными исследуются среднеазиатские и сибирские половецкие статуи. В этом направлении активно работали А.Д. Грач, Л.Р. Кызласов и Я.А. Шер. Основоположной является монографическая работа Л.А. Евтюховой «Каменные изваяния Южной Сибири и Монголии» [Евтюхова, 1952]. Большая работа по типологии каменных изваяний была проделана Г.А. Федоровым-Давыдовым.

Важнейшую роль в освещении данного вопроса играют и археологические раскопки. Два кургана с каменными идолами на вершинах были раскопаны Е. П. Трефильевым [Трефильев, 1905 , с. 142-144]. В.А. Городцов [Городцов, 1905, с. 215] исследовал восемь курганов с каменными половецкими бабами. Однако последним было высказано мнение, что каменные идолы могут быть не связаны с погребениями курганов, на которых они были установлены. На рубеже XX-XXI вв. на территории Ростовской области ряд исследований половецких погребальных комплексов провели Л.С. Ильюков, С.В. Гуркин, П.А. Ларенок и др. [Гуркин, 1991; Ларенок, 2001].

Ценные сведения дают нам и письменные исторические источники. Это упоминания в своих произведениях современниками обитателями половецкой степи, такими как Низами Ганджеви, Вильгельм (Гильом) Рубрук. Информацию о мире кочевников хранят в себе такие памятники литературного искусства, как: «Слово о полку Игореве» XII в., описание карты территорий всей России и соседних государств «Книги Большому Чертежу» XVII века.

Наряду со всеми вышеперечисленными трудами необходимо выделить фундаментальную работу С.А. Плетневой «Половецкие каменные изваяния», посвященную половец- ким изваяниям отдельно стоящей группы южнорусских и поволжских степей по классификации Я.А. Шера [Шер, 1966, с. 3-4, 3844]. Опираясь на материалы монографической работы Светланы Александровны Плетневой, удалось установить культурную принадлежность находки, проследить аналогии с уже известными статуями и установить места их хранения, составить подробное описание и классифицировать изваяние по ряду высеченных в камне элементов.

Каменный артефакт был найден автором случайно. Летом 2018 г. при археологических работах на кремневой мастерской «Денисово-Николаевка I» обследовались окрестности исследуемого памятника археологии. На предмет обнаружения новых мест концентрации подъемного кремневого материала осматривалась грунтовая дорога, проходящая по центру хутора, возделываемые и заброшенные хуторские огороды, где и была зафиксирована находка. Местом обнаружения каменного половецкого идола стала юго-западная окраина хут. Денисово-Николаевка Куйбышевского района Ростовской области, в 455 м к северо-востоку от восточной границы памятника археологии - кремневой мастерской «Денисово-Николаевка I», на левом берегу реки Левый Тузлов.

Статуя лежала на спине, слегка присыпанная землей и каменными плитками (пластушкой), за территорией одного из частных подворий со стороны «заднего» двора. По свидетельствам немногочисленных местных жителей (на момент обследования в хут. Денисово-Николаевка насчитывалось 7 жилых дворов) причудливый камень с лицом видели когда-то на противоположном, правом берегу p. Левый Тузлов, напротив хутора. Затем долгое время статуя находилась в реке - была затоплена. Очевидно, что на окраину хутора «баба» попала в результате любопытства одного из местных жителей. По-видимому, камень был доставлен сюда силами сельскохозяйственной техники (трактора), вследствие чего и получил повреждения - был отколот верхний фрагмент изваяния, но остался на своем месте и подлежит реставрации, это хорошо видно на фотоснимке (рис. 1). Можно предположить, что изначально каменный идол был установлен на высоком холмистом пра- 
вобережье р. Левый Тузлов, там и сейчас остается множество курганов, потревоженных ежегодной распашкой. Камень мог быть перемещен и просто скинут вниз во время расчистки новых сельскохозяйственных угодий.

Найденный экземпляр относительно удовлетворительной сохранности, покрыт известковым налетом, поверхность камня выветрена, сильно оббита. Статуя выполнена на уплощенной прямоугольной плите серого твердого мелкозернистого песчаника. Каменная скульптура весит порядка 100 кг и имеет следующие параметры: длина - 111 см, ширина 44 см, толщина плиты -16 см.

Статуя относится к типу мужских скульптур, предположительно к стоящим изваяниям. По способу изображения элементов и их «рельефности» может быть отнесена к I типу: «...в I тип заключены статуи, сделанные из более или менее плоских плит, в технике низкого барельефа, местами переходящего в гравировку. На лицах, как правило, обозначены брови и нос, глаза, усы, иногда острые бородки, на плоском тулове слегка приподняты барельефом или прочерчены руки и сосуд, ног нет. Спина без деталей, совершенно плоская» [Плетнева, 1974, с. 61]. Выраженный антропоморфный силуэт отсутствует. Общий абрис скульптуры может быть отнесен к I типу [Плетнева, 1974, с. 55] ${ }^{1}$. Массивная, «утяжеленная» фигура, без шеи и четко выраженной линии плеч.

Овал лица округлый, с большими щеками, круглым полным массивным подбородком. Нос выпуклый, прямой, без ноздрей, лицо безбровое, глаза не выражены, прослеживаются интуитивно. Особенно хорошо элементы лица скульптуры читаются на графическом рисунке $^{2}$ (рис. 2). Ниже на правой стороне груди ближе к центральной оси скульптуры расположен рельефный круглый элемент диаметром $6 \mathrm{~cm}$ - фрагмент нагрудного ремня с бляхами [Плетнева, 1974, с. 26] (часть мужского половецкого оборонительного доспеха). Очевидно, на левой стороне груди симметрично располагался идентичный элемент, утраченный вследствие повреждения скульптуры.

Руки выполнены грубо, детализация кистей и пальцев отсутствует. Правая рука хорошо читается в средней части скульптуры, в области живота. Левая рука прослеживает- ся более полно, утончена в запястье по сравнению с правой. Чаша выполнена в форме цилиндрического сосуда. Дно сосуда чуть шире по сравнению с более узким горлом. Изображение ритуального сосуда можно отнести к I типу по типологии С.А. Плетневой [Плетнева, 1974, с. 50-51]. Нижняя часть статуи отсутствует, на оставшейся части с косым сколом слабо выражена верхняя бедренная часть ног.

Тыльная часть, или спина, статуи либо не подвергалась обработке и сохранила естественную фактуру камня, либо также была деформирована массивным сколом. Продольные торцы статуи обработаны грубо, не имеют рельефных изображений.

Подобная форма, абрис скульптуры, изображение лица не были встречены в каталоге половецких каменных изваяний в вышеуказанной монографии С.А. Плетневой. Однако можно выделить отдаленно схожие статуи. По форме каменной плиты и количеству основных рельефных деталей сходство может быть замечено с изваянием № 910 в таблице 51 (хранится в Новочеркасском музее истории казачества) [Плетнева, 1974, с. 98, 167]. Также по форме и типу каменной заготовки (плиты) аналогична каменная баба из коллекции Азовского музея, описанная в каталоге под № 926 в таблице 53 [Плетнева, 1974, с. 98-99, 169].

В целом найденное изваяние производит впечатление неоконченного либо грубо выполненного и предположительно может быть отнесено к концу XII - началу XIII в., позднему периоду изготовления подобных скульптур. Автор может лишь выразить свои предположения, так как изваяние было обнаружено отдельно от погребального комплекса - кургана, на котором было установлено. Безусловно, комплексные археологические исследования в контексте курганного могильника могли дать более точную информацию относительно обнаруженной находки.

В конце XII в. происходит заметное упрощение и примитивизация статуй. Перестали декорировать спины и изображать детали причесок и нарядов, убрали детализацию костюмов и с лицевой стороны. Нередко даже лица статуй оставляли гладкими, без рисунка лица. Вполне вероятно, это могло быть связано с тем, что статуи раскрашивали. На хоро- 
шо отшлифованной поверхности можно было нарисовать сложный и красивый рисунок, дать большую выразительность.

Сегодня проблема сохранения и изучения каменных изваяний очень актуальна. Большое количество каменных скульптур просто не дошло до нашего времени. Большинство из них были частично разбиты или полностью уничтожены, либо хранятся в частных коллекциях. Множество курганов с установленными на них каменными идолами были потревожены сельскохозяйственной деятельностью. Камень могли использовать в бытовых целях, для строительства и хозяйственных нужд, не обращая внимания на его историческую и культурную ценность. Еще более ста лет назад выдающимся ученым Н.И. Веселовским было высказано обоснованное опасение: «С присоединением степной полосы к Российской империи каменные бабы было начали исчезать с курганов; их беспрепятственно свозили или для хозяйственных надобностей, или для украшения помещичьих усадеб» [Веселовский, 1915, с. 418].

Подобные находки на территории Южного федерального округа на сегодняшний день являются большой редкостью. Несмотря на уже проделанную работу историков и археологов по этой проблеме, каждый новый найденный экземпляр способен дать нам новые данные о сложном и, без сомнения, многогранном степном кочевом мире. 
A.Yu. Danilchenko. The Polovtsian Stone Woman from the Outskirts of the Denisovo-Nikolaevka Farmstead

\section{ИЛЛЮСТРАЦИИ}

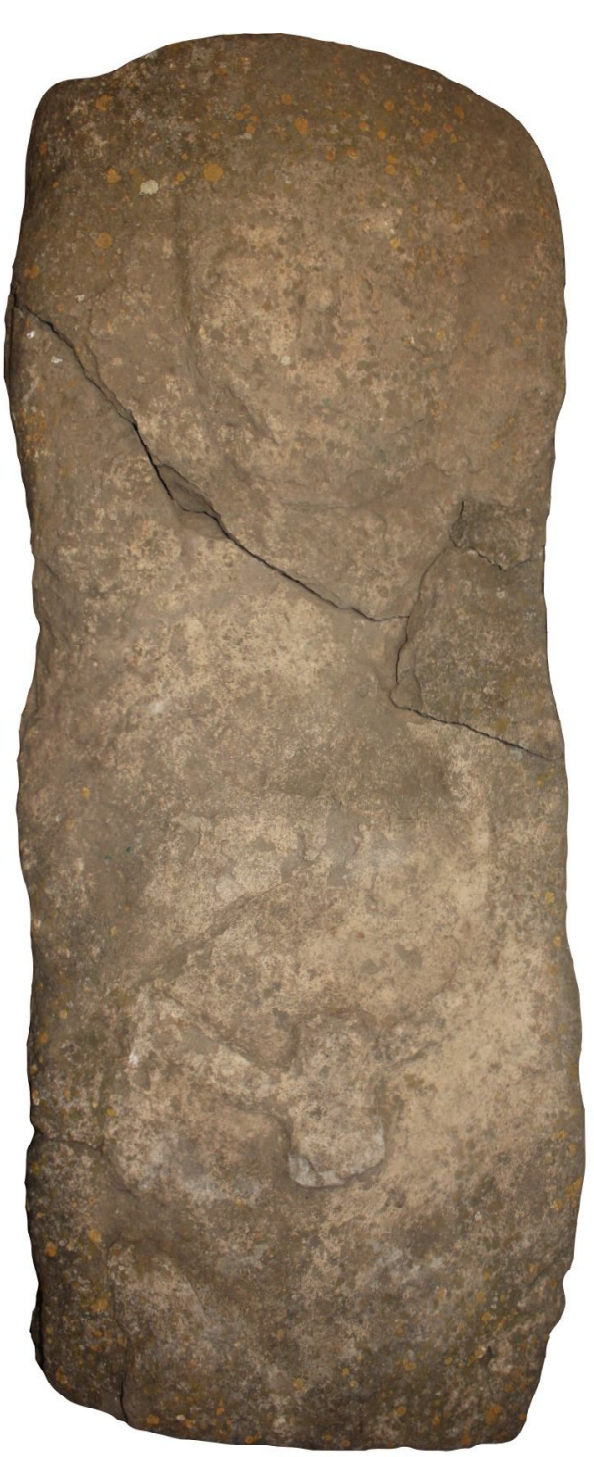

$8 \mathrm{~cm} 0$

$+1+1+1$

Рис. 1. Фотография Половецкого каменного изваяния

Fig. 1. Photo of the Polovtsian stone sculpture 


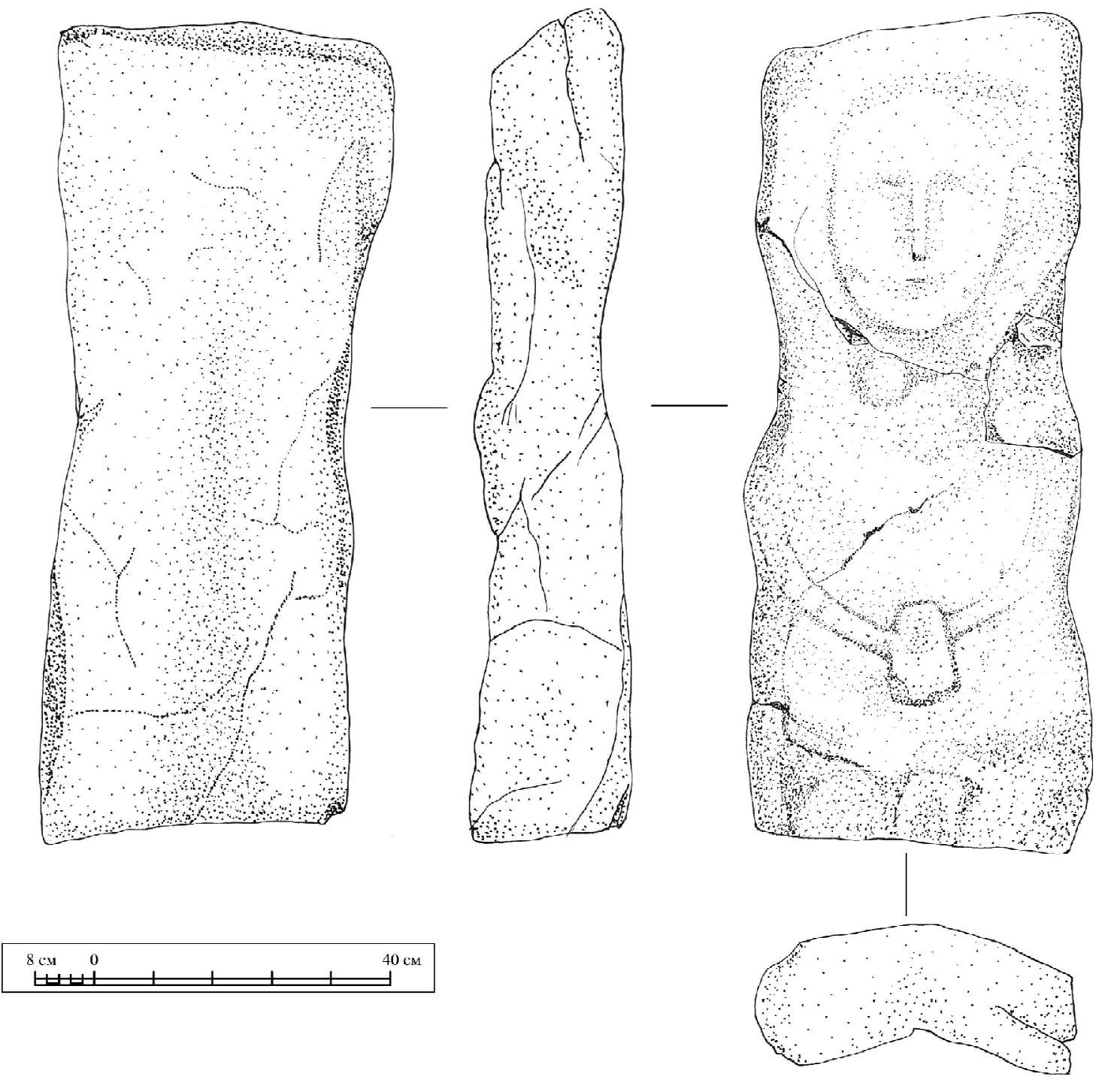

Рис. 2. Графический рисунок Половецкого каменного изваяния

Fig. 2. Graphical illustration of the Polovtsian stone sculpture 


\section{ПРИМЕЧАНИЯ}

${ }^{1}$ В связи с утраченным нижним фрагментом статуи и отсутствием проработки на ее тыльной стороне (спине) нет возможности с точностью определить тип данного изваяния - стоящий или сидящий.

${ }^{2}$ Автор выражает особую благодарность А.Г. Щипановой за выполненные рисунки каменной скульптуры.

\section{СПИСОК ЛИТЕРАТУРЫ}

Веселовский Н. И., 1915. Современное состояние вопроса о «каменных бабах» или «балбалах» // Записки Одесского Общества Истории и Древностей. Т. ХXXII. Одесса. С. 408-444.

Городцов В. А., 1905. Результаты археологических исследований в Изюмском у. Харьковской губ. 1901 // Труды ХІІ Археологического съезда. Т. I. М. С. 174-225.

Гуркин С. В., 1991. Святилище половецкого времени с каменным изваянием на Нижнем Дону // Историко-археологические исследования в Азове и на Нижнем Дону. 1990. Азов. Вып. 10. C. $103-112$.

Евтюхова Л. А., 1952. Каменные изваяния Южной Сибири и Монголии // Материалы и исследования по археологии Сибири. № 24. Т. І. М. : AHCCCP. C. $72-120$.

Ларенок П. А., 2001. Половецкие изваяния из фондов Таганрогского музея-заповедника // Донская археология. № 1-2. Ростов н/Д : Изд-во РГУ. С. 79-88.

Плетнева С. А., 1974. Половецкие каменные изваяния // Археология СССР. Свод археологических источников. Вып. Е4-02. М. : Наука. 200 с.

Трефильев Е. П., 1905. Курганы с каменными бабами Купянского уезда Харьковской губернии
// Труды ХІІ Археологического Съезда. Т. I. M. C. 141-144.

Шер Я. А., 1966. Каменные изваяния Семиречья. М. ; Л. : Наука. 140 с.

\section{REFERENCES}

Veselovskyi N.I., 1915. Current Status of the Issue of "Stone Women" or "Balbals". Zapiski Odesskogo obshchestva istorii i drevnostey, vol. XXXII. Odessa, pp. 408-444. (in Russian).

Gorodtsov V.A., 1905. The Results of Archaeological Research in the Izyum Settlement of the Kharkiv Province, 1901. Trudy XII Arkheologicheskogo syezda, vol. I. Moscow, pp. 174-225. (in Russian).

Gurkin S.V., 1991. The Sanctuary of Polovtsian Time with a Stone Statue on the Lower Don. Istorikoarkheologicheskie issledovaniya $v$ Azove i na Nizhnen Donu, 1990, Azov, iss. 10, pp. 103-112. (in Russian).

Evtyukhova L.A., 1952. Stone Statues of Southern Siberia and Mongolia. Materialy i issledovaniya po arkheologii Sibiri, no. 24, vol. I. Moscow, AN SSSR Publ., pp. 72-120. (in Russian).

Larenok P.A., 2001. Polovtsian Statues from the Collections of the Taganrog Museum-Reserve. Donskaya arkheologiya, no. 1-2. Rostov-onDon, Izd-vo RGU, pp. 79-88. (in Russian).

Pletneva S.A., 1974. Polovtsian Stone Statues. Arkheologiya SSSR. Svod arkheologicheskih istochnikov, iss. E4-02. Moscow, Nauka Publ. 200 p. (in Russian).

Trefilyev E.P., 1905. Barrows with Stone Women of the Kupyansky Settlement of the Kharkiv Province. Trudy XII Arkheologicheskogo syezda, vol. I, Moscow, pp. 141-144. (in Russian).

Sher Ya.A., 1966. Stone statue of Semirechye. Moscow; Leningrad, Nauka Publ. 140 p. (in Russian).

\section{Information about the Author}

Aleksey Yu. Danilchenko, Archaeologist, Researcher of Objects of Cultural Heritage - Project CJSC, Ulyanovskaya St., 50, 344002 Rostov-on-Don, Russian Federation, adanil4enko@ya.ru.

\section{Информация об авторе}

Алексей Юрьевич Данильченко, археолог, научный сотрудник ЗАО «Объекты культурного наследия - проект», ул. Ульяновская 50, 344002 г. Ростов-на-Дону, Российская Федерация, adanil4enko@ya.ru. 